\title{
Craig R. Lundahl and Harold A. Widdison Respond
}

To the Editor:

Leslee A. Morabito offers comments on our two articles, "Social Positions in the City of Light" (Lundahl and Widdison, 1993) and "The Physical Environment in the City of Light" (Widdison and Lundahl, 1993), and a suggestion to focus on the symbolism of near-death experiences (NDEs) in our future studies. Both of our articles evolved out of a much larger research effort in which we are doing a comprehensive content analysis of NDEs. Our efforts in this study are not designed to prove or disprove the NDE, but to learn what it can teach us about the purpose of life in general and activities, conditions, and interconnectedness between this life and the next. We have reviewed accounts from the late 1700 s to 1993 and have been im. 
pressed with the overall consistency in what has been reported and in the collective picture portrayed.

In her comments on the first article, on social positions, Morabito is concerned with our presenting the Mormon interpretation of the afterlife without describing how Mormon beliefs influence this interpretation. The purpose of the article, as explicitly stated within the article, was to identify social positions in the afterlife based on NDE accounts reported by Mormons, or members of the Church of Jesus Christ of Latter-Day Saints. Although the description of these social positions by the Mormon NDErs necessarily involves descriptions of the activities of the afterlife, the article's purpose was never to describe the afterlife specifically. An attempt was made to compare our findings on social positions with those of other near-death researchers, and their findings do corroborate the descriptions from Mormon NDErs, with two exceptions. Likely reasons for this discrepancy were discussed in the article, including the potential cultural influence on these Mormon observations. The issue of the influence of the Mormon subculture on the perception of the other world has been discussed previously (Lundahl, 1981-82).

Morabito next criticizes us for reporting in our second article "an impossibility." She argues as a statement of fact that there is no physical environment for NDErs to observe in the other world but offers no substantiation, nor does she attempt to define what she means by "physical." The descriptions in a variety of NDE accounts cited both in the article and elsewhere do not agree with her statement.

Our use of the term "physical environment" suggests that there is a substantive environment in the other world, but we do not mean to imply that it is necessarily of a physical material as we know it in this world. If there is nothing there, as Morabito suggests, then how do we explain deceased people who are seen with bodies? How do we explain NDErs who can view this world after dying (that is, the operating room activities of doctors and nurses) and then move on to view and experience yet another world? Which world is real, this world or the other world? Or are they both real? Maybe the greater reality is that both worlds are real, although we cannot yet fully explain that scientifically. How do we explain NDErs who feel grass on their feet, who eat food, who sit on benches, who walk on paths, and who touch deceased people in the other world? How do we explain their meeting and even embracing people whom they are surprised to see there, as at the time of their NDE they thought 
them to be alive, only to discover after they recovered that those people had just died (Cobbe, 1882)? How do NDErs enter into structural entities such as buildings in the other world if there is no such thing? NDErs do report they have experienced this substantive environment, that it is as real as our world or even more real than our world.

Does it require a physical brain, as Morabito suggests, to interpret such an experience? This raises the issue of the difference between the mind, which apparently is part of one's spirit (the thinking part of the person), and the physical brain, which is a part of one's physical body (the control center for the physical body) and seems to be controlled by the mind, while the spirit or soul occupies the body a view similar to one held by Wilder Penfield, "the father of neurosurgery" (Morse and Perry, 1990). In other words, it is not the physical brain that interprets anything; rather it is the mind that interprets. The difference between the mind and the physical brain is certainly suggested by the ability of NDErs to think while out-ofbody, and therefore, to interpret experiences wherever the individual might be, whether in the physical body or outside it (Lorimer, 1990; Ring, 1980; Sabom, 1982).

We appreciate Morabito's right to her own view and we respect it, but we also have some concerns of our own with her apparent disregard for scientific inquiry. First, she readily admits that her concerns are based on her own "selective" experiences, which she does not elaborate on. While we therefore have no idea what experiences she is referring to, whatever they are, they appear to contradict the NDEs of over 2.5 million Americans who claim to have seen and visited another world (Moody and Perry, 1988). It appears to us that Morabito may have a preconceived notion of what an NDE is, which she does not share with the reader. Her letter demonstrates that she knows what the NDE is not, and that evidence to the contrary is not valid. Finally, her letter indicates that she may have prematurely closed her inquiry into NDEs much like the physicists who supposedly proved that a trip to the moon would be impossible, and then turned around and put us on the moon in 1969 (Babbie, 1992).

We have attempted to present accurately in these two articles information from the observations of NDErs about what they saw and experienced during their NDEs. Morabito has mistakenly attributed these observations to our own views or beliefs. In actuality, Morabito should have addressed her concerns not to us but rather to the mil. 
lions of NDErs, from whom we have much to learn about life, death, and the state of those who have died.

\section{References}

Babbie, E. (1992). The practice of social research. Belmont, CA: Wadsworth.

Cobbe, F. P. (1882). The peak in Darien. Boston, MA: George H. Ellis.

Lorimer, D. (1990). Whole in one: The near-death experience and the ethic of interconnectedness. London, England: Arkana.

Lundahl, C. R. (1981-82). The perceived other world in Mormon near-death experiences: A social and physical description. Omega, 12, 319-327.

Lundahl, C. R., and Widdison, H. A. (1993). Social positions in the City of Light. Journal of Near-Death Studies, 11, 231.238.

Moody, R. A., Jr., and Perry, P. (1988). The light beyond. New York, NY: Bantam.

Morse, M. L., and Perry, P. (1990). Closer to the light: Learning from the near-death experiences of children. New York, NY: Villard.

Ring, K. (1980). Life at death: $A$ scientific investigation of the near-death experience. New York, NY: Coward, McCann and Geoghegan.

Sabom, M. B. (1982). Recollections of death: A medical investigation. New York, NY: Harper and Row.

Widdison, H. A., and Lundahl, C. R. (1993). The physical environment in the City of Light. Journal of Near-Death Studies, 11, 239-246.

Craig R. Lundahl, Ph.D. Department of Social Sciences Western New Mexico University P.O. Box 680 Silver City, NM 88062

Harold A. Widdison, Ph.D. Department of Sociology Box 15300

Northern Arizona University Flagstaff, AZ 86011 